\title{
Reliability Evolution of Elevators Based on the Rough Set and the Improved TOPSIS Method
}

\author{
Jian Zhang, ${ }^{1}$ Xianli Zhao, ${ }^{2}$ Canmian Liu, ${ }^{2}$ and Wei Wang ${ }^{3}{ }^{3}$ \\ ${ }^{1}$ Fujian Special Equipment Inspection and Research Institute, Fuzhou 350008, China \\ ${ }^{2}$ Business School, Sichuan University, Chengdu 610065, China \\ ${ }^{3}$ College of Harbor, Coastal and Offshore Engineering, Hohai University, Nanjing 210098, China
}

Correspondence should be addressed to Wei Wang; 13813826667@hhu.edu.cn

Received 1 April 2018; Revised 31 May 2018; Accepted 6 June 2018; Published 18 July 2018

Academic Editor: Carlos Llopis-Albert

Copyright (C) 2018 Jian Zhang et al. This is an open access article distributed under the Creative Commons Attribution License, which permits unrestricted use, distribution, and reproduction in any medium, provided the original work is properly cited.

\begin{abstract}
Focusing on reliability evaluation of elevator equipment operation, this paper builds a model for reliability evaluation of elevator equipment. First, we analyze the factors influencing the reliability of elevators and extract the initial evaluation indicators from four macro-perspectives: people, management, equipment, and environment, to build the index system for reliability evaluation of elevator equipment. And, we reduce the indicator set to remove the unnecessary indicators by using the rough set and weight the reduced indicators according to expert opinions. Finally, on this basis, we combine the grey number theory with the TOPSIS method to build an improved TOPSIS evaluation model, to evaluate the reliability of elevators and determine the optimal ordering.
\end{abstract}

\section{Introduction}

With the rapidly developing economics and society, the accelerating urbanization process, and the improving living standards in China, the passenger elevator becomes the essential vertical transport in people's daily life and society production, which is the most common special equipment in life. With the increasing number of elevators, elevator safety accidents caused by elevator failure happen frequently. The safety and reliability of elevator equipment are related to the people the safety of life and property, and any elevator accident can cause enormous loss of life and property. The statistic issued by AQSIQ shows that, in 2014, a total of 48 elevator accidents caused by various reasons killed 36 people in China; in 2015, a total of 58 elevator accidents killed 46 people in China. Therefore, the reliability of elevator safety has been concerning by the public, and it is significant to evaluate the reliability of elevators, which can find out problems instantly, get rid of security danger, and avoid the safety accidents.

Relative researchers have studied a lot on the reliability of elevator safety. Zhang applied the fuzzy evaluation method and fuzzy AHP into the evaluation system for risk of elevator system, by using the concrete mathematical model to calculate the evaluation, improving the speed and accuracy of evaluation [1]. Gu et al. provided the reliability evaluation method of elevator safety based on the risk principle, with integral various evaluation theory, including safety checklist, fuzzy evaluation, and fault tree analysis, and built the expert system of elevator safety evaluation on this basis simultaneously [2]. Liu et al. provided a risk model for using elevators based on inspection data and analyzed it [3]. Fan et al. SeungTae Park introduced the risk prediction technique into the maintenance inspection of elevators, to analyze the parts that can fail and the damages that can occur, and the maintainer maintained the elevator in terms of the risk analysis [4].

By referring to the relative literature, we find that there have been lots of researches on the safety and reliability evaluation of elevators, which have formed their own system. However, most of the researches focus on a certain system and a certain part of elevators, with few reliability researches on overall equipment. As for the selection of indicators used in reliability evaluation of elevator equipment, it mostly depends on the subjective judgments or experience, with the lack of systematic theory and a single research method, and the objectivity of evaluation results is easily called into question because of these defects. Thus, how to build an evaluation 
TABLE 1: The index system of the reliability of elevators.

\begin{tabular}{|c|c|c|}
\hline The reliability of elevators & People & $\begin{array}{l}\text { Maintainers } y_{1} \\
\text { Operators } y_{2}\end{array}$ \\
\hline \multirow{4}{*}{ The reliability of elevators } & \multirow{4}{*}{ Management } & The setting of management organization $y_{3}$ \\
\hline & & The management of maintenance and use $y_{4}$ \\
\hline & & The management regulations for elevators $y_{5}$ \\
\hline & & The management of safety and accident emergency treatment $y_{6}$ \\
\hline \multirow{2}{*}{ The reliability of elevators } & \multirow{2}{*}{ Environment } & The environment of equipment operation $y_{7}$ \\
\hline & & The condition of routine maintenance $y_{8}$ \\
\hline \multirow{3}{*}{ The reliability of elevators } & \multirow{3}{*}{ Equipment } & The evaluation of hardware $y_{9}$ \\
\hline & & The evaluation of software $y_{10}$ \\
\hline & & The interaction evaluation of hardware and software $y_{11}$ \\
\hline
\end{tabular}

system of elevator equipment completely and reasonably and explore an effective evaluation method becomes an important research subject. In view of this, this paper studies the reliability of elevator equipment from the perspective of multiobjective. First, we systematically select the indicators influencing elevator operation, from four perspectives: people, management, equipment, and environment. Secondly, we preprocess the reliability indicators of elevators by using the rough set method. Finally, we build a combination weightinggrey TOPSIS model for reliability evaluation of elevators and sort [5], to provide the reference of reliable elevator maintenance and operation plan for enterprises.

\section{The Analysis of Reliability Factor for Elevators and the Construction of Index System}

There are many factors influencing the reliability of elevators. On the basis of consulting data and spot examination, under the condition of fully acquaint with the structure of elevator system, this paper builds the index system for reliability evaluation of elevator equipment by dividing the reliability of elevators in a certain unit into the macro and micro aspects (As shown in Table 1).

From four perspectives, people, management, equipment, and environment, we determine the specific indicators evaluating the reliability of elevator equipment.

People: People, the first-class indicator, can be classified into two parts: (1) maintainers and (2) operators. They consist of the personnel factor influencing the reliability of elevators.

Equipment: The reliability indicators of main elevator equipment are subdivided into (1) safety evaluation of main parts; (2) evaluation of operating performance; (3) evaluation of safety protection devices.

Management: Based on the principle of PDCA Cycle, this paper divided the management into four indicators: (1) the setting of management organization; (2) the management of maintenance and use; (3) the management regulations for elevators; (4) the management of safety and accident emergency treatment.

Environment: The environment is comprises of (1) the environment of equipment operation and (2) the condition of routine maintenance, to build the index system of reliability evaluation.

In particular, these indicators, people, management, equipment and environment, are not independent or separated but interrelated and relying on each other, and changes in any indicator can cause the change of other indicators, to lead the deviation of business decision. Therefore, in the process of evaluating the reliability of elevator equipment, we need to fully consider the interacting factors among indicators, clarify the interrelation among indicators, and build the figure of interrelation among the indicators of the reliability of elevators, which is shown in Figure 1.

\section{Relevant Theoretical Knowledge}

\subsection{The Rough Set [6-8]}

Definition 1. Let $S=(U, R, V, f)$ be a knowledge expressing system, where $U$ is the universe, $R$ is the attribute set, $V$ is the attribute-values set, and $f$ is the information function.

Definition 2. Let $r$ be a cluster equivalence relation, where $r \in R$. When $\operatorname{ind}(R)=\operatorname{ind}(R-\{r\})$, then $r$ is not necessary in $R$ and vice versa. For each $r \in R$ is necessary in $R, R$ is independent and vice versa.

Definition 3. The set which comprises all necessary attributes in $\mathrm{R}$ is denoted as $\operatorname{core}(R)$ and called the core of the attribute set. When $P \in R$ and both $P$ and $R$ are independent, i.e., $\operatorname{ind}(P)=\operatorname{ind}(R)$, then $P$ is the reduction of $R$, which is denoted as $\operatorname{red}(P)$.

Definition 4. Where $P \subseteq R, U / \operatorname{ind}(P)$ denotes the relevant knowledge of equivalence relation family $P$ and its trail information is denoted as $\gamma(P)=1-\left(1 /|U|^{2}\right) \sum_{\mathrm{i}=1}^{\mathrm{n}}\left|x_{\mathrm{i}}^{2}\right|$.

Definition 5. Let $r_{i} \in R$. The importance of $r_{i}$ in $R$ is denoted as $\sigma_{\left(R-\left\{r_{i}\right\}\right)}\left(r_{i}\right)=\gamma(R)-\gamma\left(R-\left\{r_{i}\right\}\right)$; then the weight of $\mathrm{r}_{\mathrm{i}}$ is calculated as $\omega\left(r_{i}\right)=\sigma_{\left(R-\left\{r_{i}\right\}\right)}\left(r_{i}\right) / \sum_{\mathrm{i}=1}^{\mathrm{m}} \sigma_{\left(R-\left\{r_{i}\right\}\right)}\left(r_{i}\right)$.

3.2. The Grey Number Theory. Grey number generally refers to the number without determined value [9], and the value can only be determined by scope; usually we use " $\otimes$ " to 


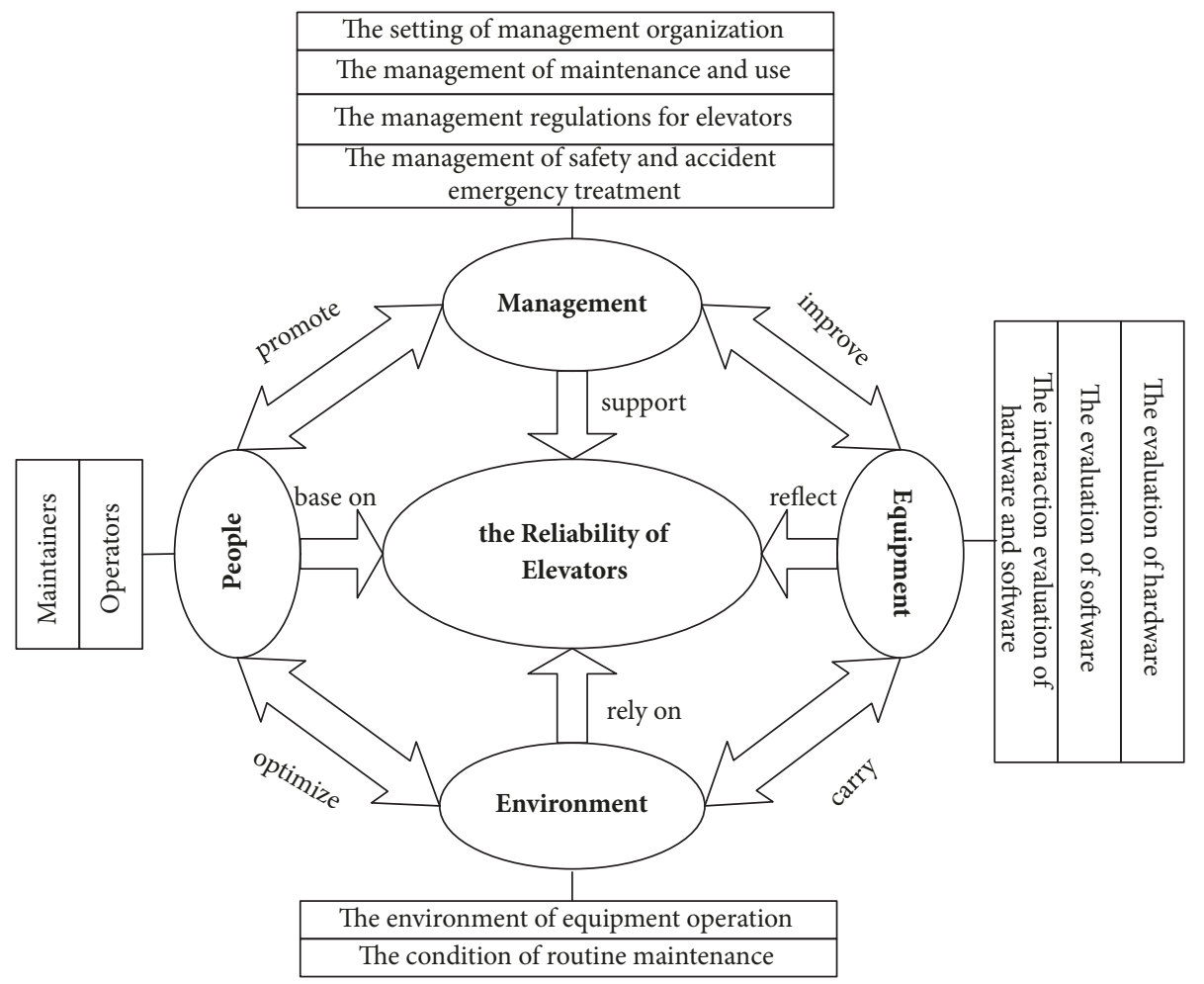

FIGURE 1: The figure of interrelation among the indicators of the reliability of elevators.

denote the grey number; for instance, the grey number of $x$ is denoted as $\otimes x=[\underline{\otimes} x, \bar{\otimes} x]$, where $\underline{\otimes} x$ and $\bar{\otimes} x$ are denoted as the upper and lower bounds, respectively.

\section{The Model for Evaluating the Reliability of Elevators}

Among the amount of data of the reliability of elevators, not all the data have the influence on the reliability of elevators. To accurately capture the key indicators and effectively evaluate the reliability of elevators, we need to filter the indicators. For this, this paper builds the model for index evaluation based on the rough set preprocessing, which is shown in Figure 2.

This model reduces the initial indicators of elevator equipment by using the rough set theory firstly, to get rid of the unnecessary indicators, obtaining the simple and effective index system. And, the grey number theory is applied to the TOPSIS [10] matrix, and the weights of reduced indicators can be determined by using the combination weighting method. In this paper, the objective weights of indicators are determined by using the rough set then combined with the subjective weights of experts to determine the final weights by weighted calculation. Finally, the evaluation result of the reliability of elevators cab be deduced by calculating the paste progress of grey ideal solution. The steps are shown as follows.

Step 1 (build the initial evaluation index system). According to the character of elevator equipment, we select the evaluation indicators and determine the evaluation index system from four aspects: people, equipment, environment, and management. Suppose that there are m elevators, which are denoted as $x_{1}, x_{2}, x_{3}, \ldots x_{m}$, respectively; there are $\mathrm{n}$ indicators, which are denoted as $y_{1}, y_{2}, y_{3} \cdots y_{\mathrm{n}}$, respectively. The weight of each indicator is denoted as $\omega_{j}$, for $j=$ $1,2,3 \cdots \mathrm{n}$.

Step 2 (build the decision matrix based on the grey theory). According to the scoring interval and information identification of the reliability indicators of elevators by experts, we take the corresponding grey number, which is expressed as follows: for $i=1,2,3 \cdots, \mathrm{m}, j=1,2,3 \cdots, \mathrm{n}$, and build the grey decision matrix as

$$
A(\bigotimes)=\begin{array}{cccc}
y_{1} & y_{2} & \cdots & y_{\mathrm{n}} \\
x_{1} \\
x_{2} \\
\vdots \\
x_{\mathrm{m}}
\end{array}\left[\begin{array}{cccc}
\otimes x_{11} & \bigotimes x_{12} & \cdots & \otimes x_{1 \mathrm{n}} \\
\otimes x_{21} & \bigotimes x_{22} & \cdots & \otimes x_{2 \mathrm{n}} \\
\vdots & \vdots & \vdots & \vdots \\
\otimes x_{\mathrm{m} 1} & \bigotimes x_{\mathrm{m} 2} & \cdots & \otimes x_{\mathrm{mn}}
\end{array}\right]
$$

Step 3 (reduce the indicators by using the rough set theory). The reduction of indicators is to get rid of the redundant indicators of the reliability of elevators and form the new evaluation indicators, to simplify the evaluation. The specific steps are as follows:

(1) Establish the information system of evaluation indicators;

(2) Discretize data; the rough set theory is only able to process the discrete data, so the sample data need to be discretized before reducing the initial data. 

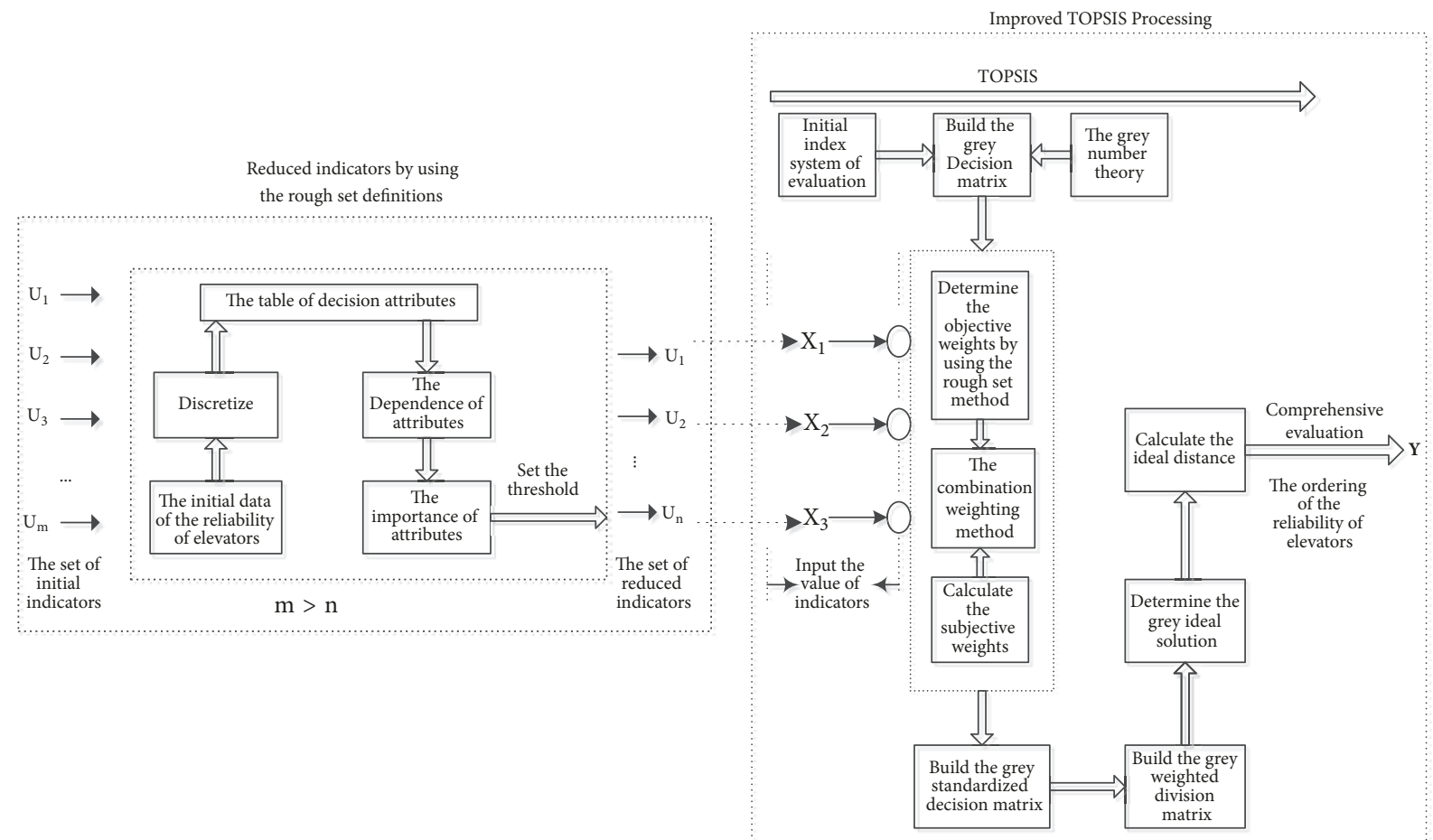

FIgURE 2: The model for reliability evaluation of elevators.

(3) Reduce indicators.

Step 4 (determine the weights). This paper adopts the combination weighting method combining the subjective weighting method by expert scoring with the objective weighting method by calculating the weights through the rough set, to determine the weights of indicators, finding the weights of indicators as reasonable and formal as possible. The specific steps are as follows:

(1) $Q_{i}$ denotes the weight of the $i$ th attribute judged by experts;

(2) $P_{i}$ denotes the weight of the $i$ th attribute determined by the rough set;

(3) Combine the subjective weights with the objective weights to find the combined weight, which is expressed as

$$
I_{i}=\alpha Q_{i}+(1-\alpha) P_{i}
$$

where $\alpha$ is the experiential factor.

Step 5 (build the grey standardized decision matrix). To get rid of the influencing among dimension and make the comparison between different attributes, we standardize the grey matrix by the following:

$$
\begin{aligned}
& \bigotimes r_{i j}= \frac{\bigotimes x_{i j}}{\sqrt{\sum_{i=1}^{\mathrm{n}} \bigotimes x_{i j}^{2}}}, \\
& \quad \text { for } i=1,2,3 \cdots, \mathrm{m}, j=1,2,3 \cdots, \mathrm{n} .
\end{aligned}
$$

Step 6 (build the grey weighted division matrix). To calculate the weighted matrix $\otimes s_{i j}=\left[s_{i j}, \overline{s_{i j}}\right]$, where $\otimes s_{i j}=\omega_{j} \times \otimes r_{i j}$, for $i=1,2,3 \cdots, \mathrm{m}, j=1,2,3 \cdots, \mathrm{n}, \omega_{j}$ is denoted as the indicator weight of combined weight.

Step 7 (determine the grey ideal solution). Let $\underline{t}_{j}=\max _{i} \underline{s}_{i j}$, $\overline{t_{i j}}=\max _{i} \overline{s_{i j}}, \underline{s}_{j}=\min _{i} \underline{s}_{\mathrm{ij}}$, and $\overline{s_{j}}=\min _{i} \overline{s_{i j}}$;

The positive ideal solution is $\otimes X^{+}=\left(\left[\underline{t_{1}}, \overline{t_{1}}\right],\left[\underline{t_{2}}, \overline{t_{2}}\right]\right.$, $\left.\cdots,\left[t_{n}, \overline{t_{n}}\right]\right)$;

The negative ideal solution is $\otimes X^{-}=\left(\left[\underline{s_{1}}, \overline{s_{1}}\right],\left[\underline{s_{2}}, \overline{s_{2}}\right], \cdots\right.$, $\left.\left[\underline{s_{n}}, \overline{s_{n}}\right]\right)$.

Step 8 (calculate the ideal distance). The ideal distance of the reliability of each elevator equipment and the distance to the positive ideal solution are

$$
\begin{array}{r}
L\left(\bigotimes X_{i}, \bigotimes X^{+}\right)=\sqrt{\left(\mathrm{l}_{i 1}^{+}\right)^{2}+\left(\mathrm{l}_{i 2}^{+}\right)^{2}+\cdots+\left(\mathrm{l}_{i n}^{+}\right)^{2}}, \\
i=1,2,3 \cdots, \mathrm{m}
\end{array}
$$

The distance to the negative ideal solution is

$$
\begin{array}{r}
L\left(\bigotimes X_{i}, \bigotimes X^{-}\right)=\sqrt{\left(\mathrm{l}_{i 1}^{-}\right)^{2}+\left(\mathrm{l}_{i 2}^{-}\right)^{2}+\cdots+\left(\mathrm{l}_{i n}^{-}\right)^{2}}, \\
i=1,2,3 \cdots, \mathrm{m}
\end{array}
$$

The close-degree to grey ideal solution is

$$
C_{i}=\frac{L\left(\bigotimes X_{i}, \bigotimes X^{-}\right)}{L\left(\bigotimes X_{i}, \bigotimes X^{-}\right)+L\left(\bigotimes X_{i}, \bigotimes X^{+}\right)},
$$

sorted by the results. 
TABLE 2: The raw data of indicators evaluation.

\begin{tabular}{|c|c|c|c|c|c|c|c|c|c|c|c|}
\hline & $y_{1}$ & $y_{2}$ & $y_{3}$ & $y_{4}$ & $y_{5}$ & $y_{6}$ & $y_{7}$ & $y_{8}$ & $y_{9}$ & $y_{10}$ & $y_{11}$ \\
\hline$x_{1}$ & good & poor & $\begin{array}{l}\text { between } \\
\text { average } \\
\text { and good }\end{array}$ & average & very good & $\begin{array}{c}\text { better } \\
\text { than } \\
\text { average }\end{array}$ & average & very good & good & good & very good \\
\hline$x_{2}$ & average & good & average & good & average & good & poor & very good & good & average & $\begin{array}{c}\text { better } \\
\text { than } \\
\text { average }\end{array}$ \\
\hline$x_{3}$ & poor & average & very good & $\begin{array}{c}\text { better } \\
\text { than } \\
\text { average }\end{array}$ & $\begin{array}{c}\text { worse } \\
\text { than } \\
\text { average }\end{array}$ & $\begin{array}{c}\text { better } \\
\text { than } \\
\text { average }\end{array}$ & poor & good & poor & very good & good \\
\hline$x_{4}$ & $\begin{array}{l}\text { poor but } \\
\text { not very } \\
\text { poor }\end{array}$ & poor & very good & good & poor & poor & average & good & $\begin{array}{c}\text { better } \\
\text { than } \\
\text { average }\end{array}$ & very good & $\begin{array}{c}\text { better } \\
\text { than } \\
\text { average }\end{array}$ \\
\hline$x_{5}$ & good & poor & very good & average & average & $\begin{array}{c}\text { worse } \\
\text { than } \\
\text { average }\end{array}$ & $\begin{array}{c}\text { poor but } \\
\text { not very } \\
\text { poor }\end{array}$ & average & good & average & good \\
\hline
\end{tabular}

\section{Case Study}

5.1. Data Sources. This paper takes five elevators from a special equipment corporation in Fujian as an example, begins with the 11 indicators determined by 4 perspectives: people, management, environment, and equipment, and asks experts to carry out actual analysis and evaluation of each equipment. The raw data of indicators evaluation is shown in Table 2.
This article selects the evaluation set $\{[0.8,1.0],[0.6,0.8]$, $[0.4,0.6],[0.2,0.4],[0.0,0.2]\}$ which means that it is very good, good, average, poor, and very poor.

5.2. Result Analysis. After experts analyze all equipment on spot, the linguistic variables of each indicator from experts should be transformed into grey number, to build the grey decision matrix shown as follows:

$\mathrm{A}(\bigotimes)$

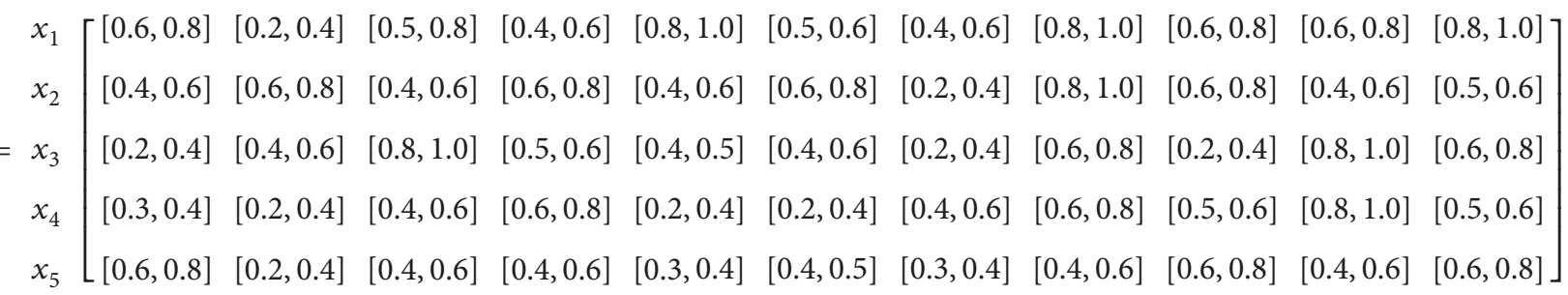

To use $[0,40] \longrightarrow 1,[40,80] \longrightarrow 2$, [80, 100] $\longrightarrow 3$ we discretize the information in the sample as shown in Table 3.

According to the theory of rough set and its reduction function in the above, we can elicit that the setting of management organization $y_{3}$ and the management regulations for elevators $y_{5}$ have no obvious influence on elevators. So, the simplified index system is

$$
\begin{aligned}
& Y=\left(y_{1}, y_{2}, y_{4}, y_{6}, y_{7}, y_{8}, y_{9}, y_{10}, y_{11}\right) \text {. } \\
& \begin{array}{l}
x_{1} \\
x_{2}
\end{array}\left[\begin{array}{llllllllll}
{[0.6,0.8]} & {[0.2,0.4]} & {[0.4,0.6]} & {[0.5,0.6]} & {[0.4,0.6]} & {[0.8,1.0]} & {[0.6,0.8]} & {[0.6,0.8]} & {[0.8,1.0]} \\
0.40 .6,0.8] & {[0.6,0.8]} & {[0.6,0.8]} & {[0.2,0.4]} & {[0.8,1.0]} & {[0.6,0.8]} & {[0.4,0.6]} & {[0.5,0.6]}
\end{array}\right]
\end{aligned}
$$

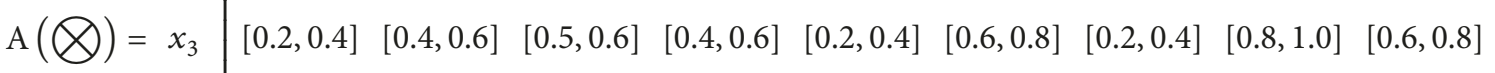

$$
\begin{aligned}
& x_{4}[0.3,0.4][0.2,0.4][0.6,0.8][0.2,0.4][0.4,0.6][0.6,0.8][0.5,0.6][0.8,1.0][0.5,0.6] \\
& x_{5}\left[\begin{array}{lll}
0.6,0.8][0.2,0.4][0.4,0.6][0.4,0.5][0.3,0.4][0.4,0.6][0.6,0.8][0.4,0.6][0.6,0.8]
\end{array}\right.
\end{aligned}
$$


TABLE 3: The discrete initial data.

\begin{tabular}{cccccccccccc}
\hline & $y_{1}$ & $y_{2}$ & $y_{3}$ & $y_{4}$ & $y_{5}$ & $y_{6}$ & $y_{7}$ & $y_{8}$ & $y_{9}$ & $y_{10}$ & $y_{11}$ \\
\hline$x_{1}$ & 3 & 2 & 2 & 1 & 3 & 1 & 2 & 2 & 3 & 2 \\
$x_{2}$ & 3 & 2 & 1 & 1 & 3 & 1 & 2 & 2 & 3 & 2 \\
$x_{3}$ & 3 & 1 & 3 & 2 & 3 & 1 & 3 & 3 & 2 & 2 \\
$x_{4}$ & 1 & 3 & 2 & 3 & 1 & 3 & 3 & 1 & 1 & 2 \\
$x_{5}$ & 1 & 3 & 2 & 3 & 3 & 3 & 3 & 1 & 1 & 2 \\
\hline
\end{tabular}

TABLE 4: The importance of indicators.

\begin{tabular}{lcccccccc}
\hline indicator & $y_{2}$ & $y_{4}$ & $y_{6}$ & $y_{7}$ & $y_{8}$ & $y_{9}$ & $y_{10}$ & $y_{11}$ \\
importance & 0.4 & 0.4 & 0.34 & 0.2 & 0.2 & 0.2 & 0.5 & 0.5 \\
\hline
\end{tabular}

TABLE 5: The weights of indicators.

\begin{tabular}{lccccccccc}
\hline indicator & $y_{1}$ & $y_{2}$ & $y_{4}$ & $y_{6}$ & $y_{7}$ & $y_{8}$ & $y_{9}$ & $y_{10}$ & $y_{11}$ \\
weight & 0.056 & 0.15 & 0.15 & 0.13 & 0.07 & 0.07 & 0.07 & 0.19 & 0.19 \\
\hline
\end{tabular}

Calculating the importance of each indicator by using the concept and equations of the rough set

$$
\begin{aligned}
\sigma_{\left(R-\left\{r_{i}\right\}\right)}\left(r_{i}\right) & =\gamma(R)-\gamma\left(R-\left\{r_{i}\right\}\right) \\
\gamma(R) & =0.8 \\
\gamma\left(R-\left\{y_{1}\right\}\right. & =0.65
\end{aligned}
$$

Find $\sigma_{\left(R-\left\{y_{1}\right\}\right)}\left(y_{1}\right)=\gamma(R)-\gamma\left(R-\left\{r_{1}\right\}\right)=0.15$.

Similarly, this is shown in Table 4.

The weight of each indicator can be elicited by equations calculating the weights of the rough set, which is shown in Table 5.

$\mathrm{A}(\bigotimes)$

$$
\begin{aligned}
x_{1} & x_{2}
\end{aligned}\left[\begin{array} { l l l l l l l l l l } 
{ [ 0 . 7 5 , 1 . 0 ] } & { [ 0 . 2 5 , 0 . 5 ] } & { [ 0 . 5 , 0 . 7 5 ] } & { [ 0 . 6 3 , 0 . 7 5 ] } & { [ 0 . 6 7 , 1 . 0 ] } & { [ 0 . 8 , 1 . 0 ] } & { [ 0 . 7 5 , 1 . 0 ] } & { [ 0 . 6 , 0 . 8 ] } & { [ 0 . 8 , 1 . 0 ] } \\
{ = } & { x _ { 3 } } \\
{ } & { x _ { 4 } } \\
{ } & { x _ { 5 } }
\end{array} \left[\begin{array}{lllllllll}
{[0.25,0.5]} & {[0.5,0.75]} & {[0.63,0.75]} & {[0.5,0.75]} & {[0.34,0.67]} & {[0.6,0.8]} & {[0.25,0.5]} & {[0.8,1.0]} & {[0.6,0.8]} \\
{[0.75,1.0]} & {[0.25,0.5]} & {[0.5,0.75]} & {[0.5,0.63]} & {[0.5,0.67]} & {[0.4,0.6]} & {[0.75,1.0]} & {[0.4,0.6]} & {[0.6,0.8]}
\end{array}\right.\right.
$$

The subjective weighted can be given by comprehensive analysis from experts with their experience and existing knowledge. Let $Q_{i}(i=1,2, \ldots n)$ be the subjective weight of each indicator from the index system $C=\left\{y_{1}, y_{2}, \cdots, y_{n}\right\}$, respectively, which satisfies $\sum_{\mathrm{i}=1}^{\mathrm{n}} Q_{i}=1$, as is shown in Table 6.

The combined weight is $I_{i}=\alpha Q_{i}+(1-\alpha) P_{i}$, where $\sigma$ is the experiential factor. According to the actual situation, we set the experiential factor as 0.2 with synthetic consideration, to get the comprehensive weights shown in Table 7 .

To standardize the grey matrix, we standardize the reduced grey matrix by using the rough set method.

To weight the grey matrix, get the weighted grey matrix.

$$
\begin{aligned}
& \text { A (め) }
\end{aligned}
$$

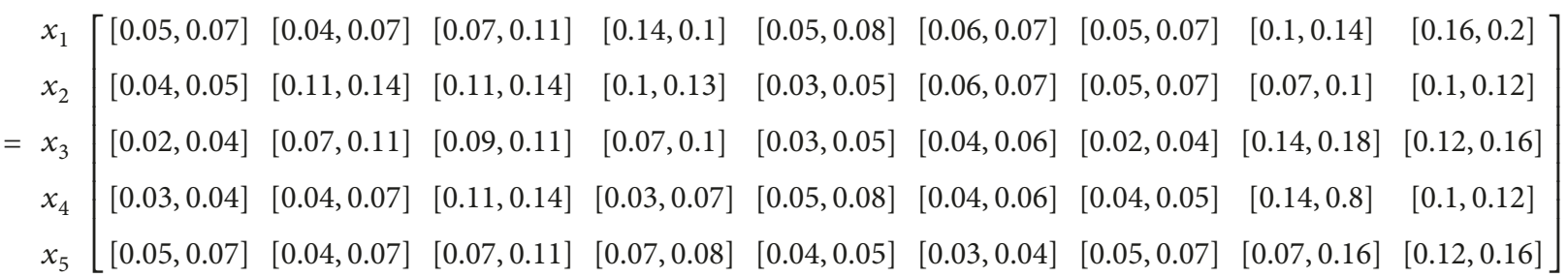


TABLE 6: The subjective weights of indicators.

\begin{tabular}{lccccccccc}
\hline indicator & $y_{1}$ & $y_{2}$ & $y_{4}$ & $y_{6}$ & $y_{7}$ & $y_{8}$ & $y_{9}$ & $y_{10}$ & $y_{11}$ \\
weight & 0.106 & 0.1 & 0.1 & 0.13 & 0.12 & 0.07 & 0.07 & 0.13 & 0.25 \\
\hline
\end{tabular}

TABLE 7: The comprehensive weights of indicators.

\begin{tabular}{|c|c|c|c|c|c|c|c|c|c|}
\hline indicator & $y_{1}$ & $y_{2}$ & $y_{4}$ & $y_{6}$ & $y_{7}$ & $y_{8}$ & $y_{9}$ & $y_{10}$ & $y_{11}$ \\
\hline weight & 0.07 & 0.14 & 0.14 & 0.13 & 0.08 & 0.07 & 0.07 & 0.18 & 0.2 \\
\hline
\end{tabular}

TABLE 8: The close-degree of evaluated elevators.

\begin{tabular}{lccccc}
\hline elevator & $x_{1}$ & $x_{2}$ & $x_{3}$ & $x_{4}$ & $x_{5}$ \\
\hline close-degree & 0.53 & 0.35 & 0.41 & 0.58 & 0.39 \\
\hline
\end{tabular}

To determine the positive and negative ideal solution, the positive ideal solution is

$$
\begin{aligned}
& \bigotimes X^{+}=([0.05,0.07],[0.11,0.14],[0.11,0.14], \\
& {[0.14,0.13],[0.05,0.08],[0.06,0.07],[0.05,0.07],} \\
& [0.14,0.18],[0.16,0.16])
\end{aligned}
$$

The negative ideal solution is

$$
\begin{aligned}
& \bigotimes X^{-}=([0.02,0.04],[0.04,0.07],[0.07,0.11], \\
& {[0.03,0.07],[0.03,0.05],[0.03,0.04],[0.02,0.04],} \\
& [0.07,0.10],[0.10,0.12])
\end{aligned}
$$

To calculate the distance between each evaluation object and the ideal solution, the results are as follows:

The distance to the positive ideal solution is

$$
\begin{aligned}
& L\left(\bigotimes x_{1}, \bigotimes x^{+}\right)=0.20 \\
& L\left(\bigotimes x_{2}, \bigotimes x^{+}\right)=0.24 \\
& L\left(\bigotimes x_{3}, \bigotimes x^{+}\right)=0.17 \\
& L\left(\bigotimes x_{4}, \bigotimes x^{+}\right)=0.15 \\
& L\left(\bigotimes x_{5}, \bigotimes x^{+}\right)=0.23
\end{aligned}
$$

The distance to the negative ideal solution is

$$
\begin{aligned}
& L\left(\bigotimes x_{1}, \bigotimes x^{-}\right)=0.23 \\
& L\left(\bigotimes x_{2}, \bigotimes x^{-}\right)=0.13 \\
& L\left(\bigotimes x_{3}, \bigotimes x^{-}\right)=0.12 \\
& L\left(\bigotimes x_{4}, \bigotimes x^{-}\right)=0.21 \\
& L\left(\bigotimes x_{5}, \bigotimes x^{-}\right)=0.15
\end{aligned}
$$

To calculate the close-degree to the ideal solution of each evaluation object, the result is presented in Table 8 .

By Table 8, we can intuitively find that the ordering of the reliability of these 5 elevators is $x_{4}>x_{1}>x_{3}>x_{5}>x_{2}$. Therefore, whether regularly maintaining the equipment or lending, the specific and reasonable arrangement can be given in terms of the ordering.

\section{Conclusions}

To solve the problem on reliability evaluation of elevator equipment, this paper builds the reliability evaluation index system of elevator equipment with a microscopic perspective and conducts a comprehensive analysis combining with objective data, to reasonably find the actual reliability of evaluated elevators. The conclusions obtained by studying are as follows:

(1) According to the rough set theory and the combination weighting approach, this paper builds the multiobjective evaluation model for the reliability of elevator equipment. This model mines the relationship among indicators by using the combination weighting approach, under the condition that the key influencing factors are extracted reasonably, determining the weights of key indicators scientifically and effectively by combining with the objective data of indicators, to reasonably evaluate the reliability of several elevators.

(2) While analyzing the internal logical relationship among indicator data in the multiobjective evaluation model for the reliability of elevator equipment, we combine the qualitative analysis with quantitative calculation of indicators, providing a more reliable reference for determining the plans for elevator equipment of maintenance quantitatively.

This paper extracted the key indicators in a more reasonable way by using the rough set theory and reduced the indicators which influence the reliability of elevators not significantly. Although this method reduces amount of work on calculating to some extent, it is unable to reflect the relationship between results and indicators integrally, with certain error in sorted results. Therefore, under the circumstance of maintaining the integral data of indicators, to reduce amount of work on calculating as much as possible is the focused direction for further study. 


\section{Data Availability}

The data used to support the findings of this study are available from the corresponding author upon request.

\section{Conflicts of Interest}

The authors declare no conflicts of interest.

\section{Acknowledgments}

This research is supported by the Project of Fujian Provincial Bureau of Quality and Technical Supervision (FJQI2014055) and the Project of Fujian Provincial Bureau of Science and Technique (2016Y0021).

\section{References}

[1] G. Zhang, L. Cai, W. Zhu, and Z. Chai, "Application of evaluation model based on fuzzy analytic hierarchy process in elevator selection," Elevator World, vol. 54, no. 10, pp. 114-119, 2006.

[2] U. G. Xu-Yi and P. Zhang, "Research of Comprehensive Safety Assessment Method for Elevator System," China Safety Science Journal, vol. 18, no. 6, pp. 146-151, 2008.

[3] Y. J. Liu, W. X. Wang, and Y. C. Song, "A risk model and risk distribution for elevator in use based on historical inspection data," Machine Tool Hydraulics, vol. 12, pp. 46-51, 2015.

[4] S.-T. Park and B.-S. Yang, "An implementation of risk-based inspection for elevator maintenance," Journal of Mechanical Science and Technology, vol. 24, no. 12, pp. 2367-2376, 2010.

[5] X. L. Li, "Rough Set-based Grey-Topsis Approach to the Third Party Reverse Logistic Vendor Selection," Science and Technology Management Research, vol. 33, no. 14, pp. 67-71, 2013.

[6] Z. Pawlak, "Rough set theory and its application to data analysis," Cybernetics and Systems, vol. 29, no. 7, pp. 661-688, 1998.

[7] A. Mardani, M. Nilashi, J. Antucheviciene, M. Tavana, R. Bausys, and O. Ibrahim, "Recent Fuzzy Generalisations of Rough Sets Theory: A Systematic Review and Methodological Critique of the Literature," Complexity, vol. 2017, Article ID 1608147, 33 pages, 2017.

[8] Y. Zhu and W. Zhu, "A variable precision covering-based rough set model based on functions," The Scientific World Journal, vol. 2014, Article ID 210129, 2014.

[9] B. Zeng, C. Li, G. Chen, and W. Zhang, "Verhulst model of interval grey number based on information decomposing and model combination," Journal of Applied Mathematics, vol. 2013, Article ID 472065, 8 pages, 2013.

[10] C. L. Hwang and K. Yoon, Multiple Attribute Decision Making, Springer, Berlin Heidelberg, 1995. 


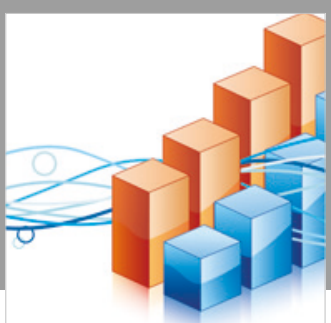

Advances in

Operations Research

\section{-n-m}
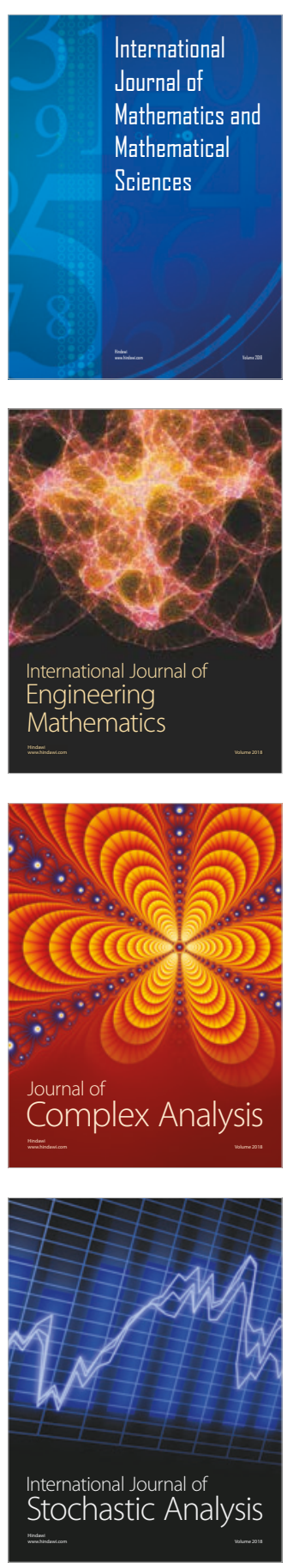
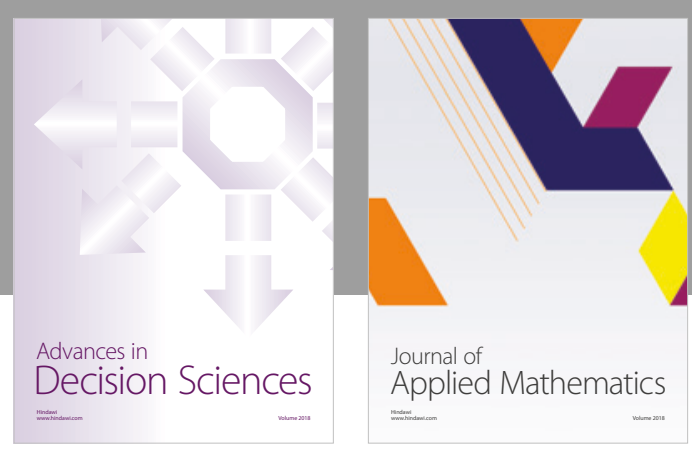

Journal of

Applied Mathematics
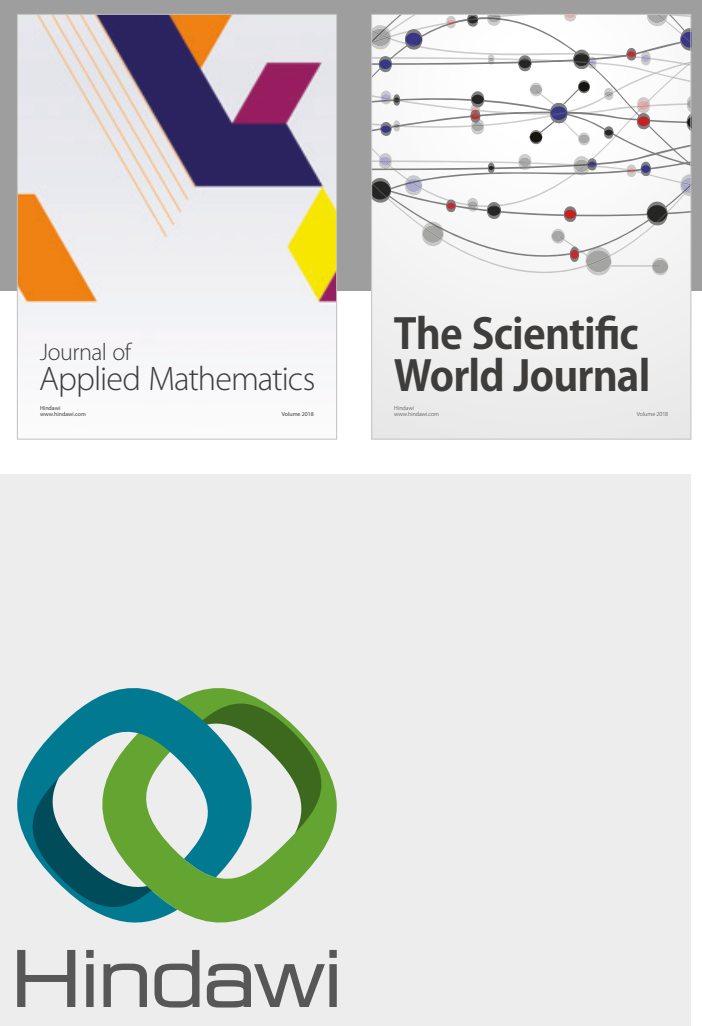

Submit your manuscripts at

www.hindawi.com

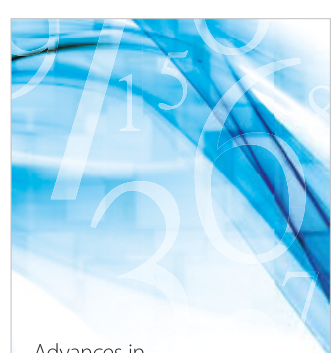

Advances in
Numerical Analysis
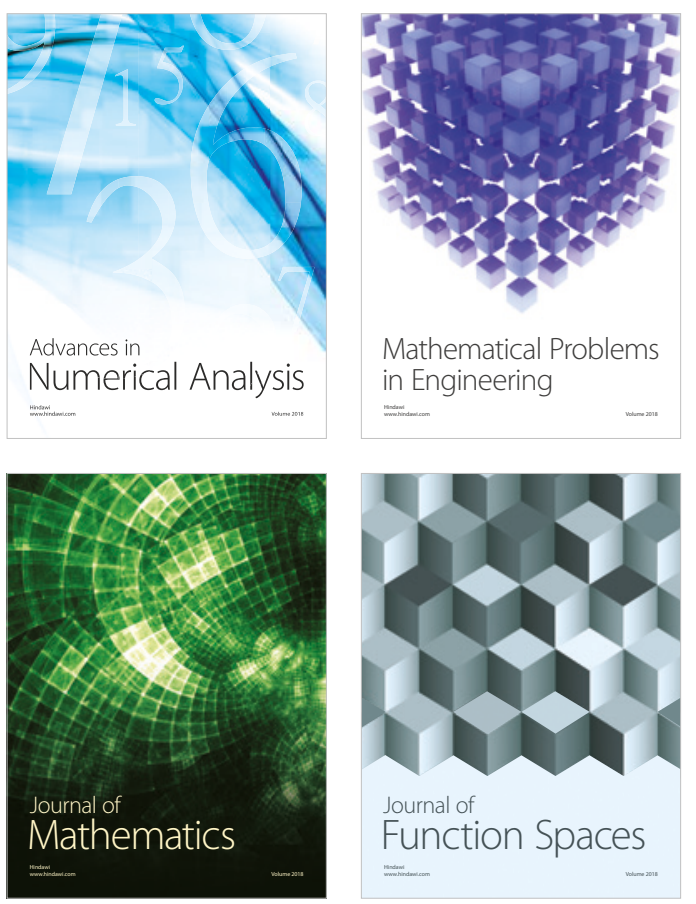

Mathematical Problems in Engineering

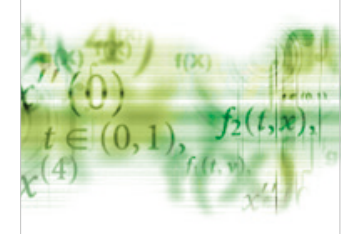

International Journal of

Differential Equations

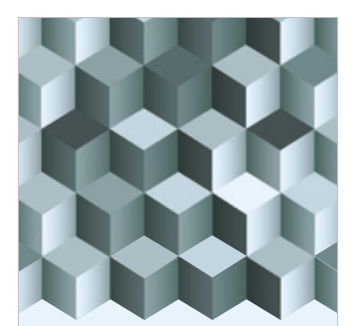

Journal of

Function Spaces

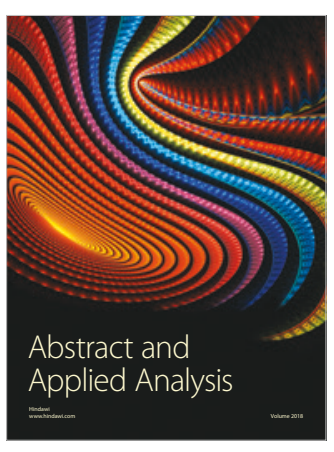

The Scientific

World Journal

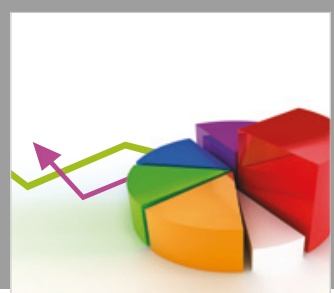

Journal of

Probability and Statistics
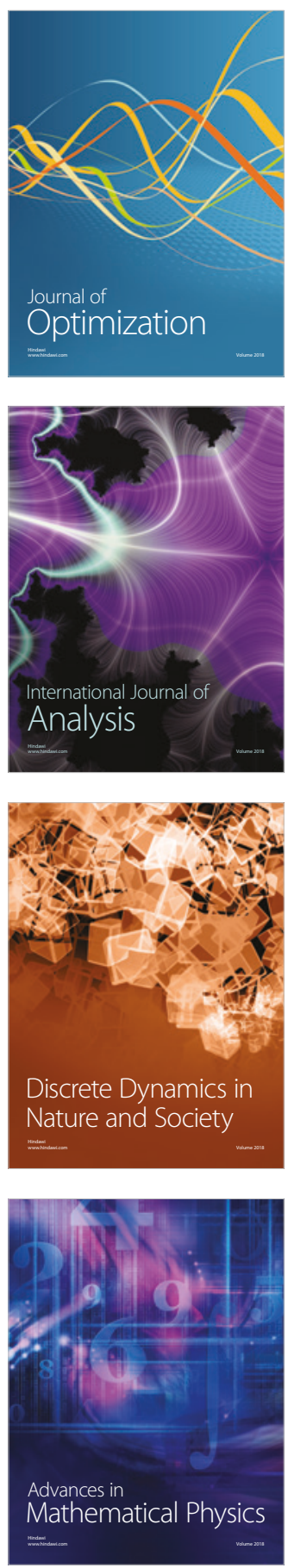